\title{
Numerical Investigation of Plastic Deformation in Two-turn Equal Channel Angular Extrusion
}

\author{
A. Mitsak \\ Laboratory of Applied Biomechanics \\ and Biomaterials \\ ENP Oran, Algeria \\ ali_mitsak@yahoo.fr
}

\author{
B. Aour \\ Laboratory of Applied Biomechanics \\ and Biomaterials \\ ENP Oran, Algeria. \\ ben_aour@hotmail.com
}

\author{
F. Khelil \\ Laboratory LML of Lille \\ University of Lille1 \\ France \\ foudil.khelil@univ-lille1.fr
}

\begin{abstract}
There has been a number of investigations in recent years reporting on the structure and properties of materials deformed to super plastic deformation (SPD). During SPD new textures can be formed and abnormal characteristics are displayed, attracting a growing research interest. Equal channel angular extrusion (ECAE) is a method often used to obtain large plastic strains. However, according to experimental results, there is a large tensile stress in the sample during deformation, which may lead in some cases, to cracking in metallic alloys and large curvature in polymeric materials. In order to overcome these drawbacks, the ECAE process can be conducted at high temperatures. But this contributes significantly to a decreased level of plastic deformation induced in the sample. Hence, a tool with multi-pass seems to be a very appropriate solution. In this paper, a new geometry die composed of two elbows has been simulated by finite element method aiming to provide an insight into the mechanisms of deformation and to determine the optimum geometry of the tool. The numerical results show that the length and the section of the second channel play a significant role on the homogeneity of the plastic strain distribution. It has been found that good homogeneity was obtained when the second channel has the same section as that of the entrance and the exit channels and with a length equal to three times of its width.
\end{abstract}

Keywords - ECAE; finite element modelling; equivalent plastic strain; friction.

\section{INTRODUCTION}

Equal channel angular extrusion (ECAE) process is an effective method to improve the physical and mechanical properties of materials without alteration of the geometric shape of the extruded samples. By varying the orientation of the sample between consecutive passes, stylish microstructures can be developed in the material. Initially, it was developed for metallic materials [1-5] but more recently, it has been applied to polymeric materials [6-9]. However, according to some obtained results, the main drawbacks of this process are the appearance of the cracking phenomenon in certain metallic alloys [3-5] and obtaining a relatively significant curvature for polymeric materials [7-9].

Several analytical approaches have been used to explain the deformation behavior of materials in the ECAE process [10-12].
However, due to the complexity of the plastic deformation induced by this process, numerical modeling becomes an indispensable tool to predict the fundamental mechanisms of the plastic yielding occurring in the extruded materials [13-15]. Hence, the finite element method (FEM) seems to be the most adequate technique to analyze the global and local deformation response of ECAE samples, to compare the effects of various parameters, and consequently, to provide fruitful information for optimum process conditions.

In order to improve the plastic strain homogeneity and circumvent the disadvantages of the traditional ECAE process, an optimization of new die geometry composed of two elbows has been proposed in this present investigation. A diagrammatic representation of this geometry is shown in Figure 1 and it may be considered as a two turn equal channel angular extrusion (2ECAE), since the sample passes by two elbows in one pass. The various effects of the geometrical parameters of the die (the length and width of the second channel) and the processing conditions (friction) on the material behavior during 2-ECAE process have been highlighted. As will be shown later, this new geometry allows us to attain higher deformation values and good homogeneity of the plastic strain distribution than that achieved by using conventional ECAE dies. Furthermore, the results obtained gave indications on the required forces for extrusion and the design guidelines of the new device of 2ECAE to be realized.

\section{GEOMETRIC ANALYSIS}

The principle of 2-ECAE process is given in Figure 1. It aims to extrude the material in a die made up of two elbows with a channel angle $\Phi$ (equal to $90^{\circ}$ in this case) and a corner angle $\Psi$ generally ranging between 0 and $90^{\circ}$. The equivalent plastic strain imposed on a sample as it passes through the first elbow can be estimated using a relationship which depends upon the two angles $\Phi=\Phi_{1}$ and $\Psi=\Psi_{1}$ as follows [2]:

$$
\varepsilon_{p}^{1}=\frac{1}{\sqrt{3}}\left[2 \cot \left(\frac{\Phi_{1}}{2}+\frac{\Psi_{1}}{2}\right)+\Psi \operatorname{cosec}\left(\frac{\Phi_{1}}{2}+\frac{\Psi_{1}}{2}\right)\right]
$$


where $\Phi_{1}$ is the internal angle between the two intersecting channels and $\Psi_{1}$ is the angle defining the outer arc of curvature where the two channels intersect in the first elbow.

The total equivalent plastic strain induced after the second pass (second elbow), if the angles are not the same as the first, can be given by:

$$
\begin{aligned}
\varepsilon_{p}^{T} & =\varepsilon_{p}^{1}+\varepsilon_{p}^{2} \\
& =\frac{1}{\sqrt{3}}\left[2 \cot \left(\frac{\Phi_{1}}{2}+\frac{\Psi_{1}}{2}\right)+\Psi \operatorname{cosec}\left(\frac{\Phi_{1}}{2}+\frac{\Psi_{1}}{2}\right)\right] \\
& +\frac{1}{\sqrt{3}}\left[2 \cot \left(\frac{\Phi_{2}}{2}+\frac{\Psi_{2}}{2}\right)+\Psi \operatorname{cosec}\left(\frac{\Phi_{2}}{2}+\frac{\Psi_{2}}{2}\right)\right]
\end{aligned}
$$

In the case where $\Psi_{1}=\Psi_{2}=\Psi$ and $\Phi_{1}=\Phi_{2}=\Phi$, becomes:

$$
\varepsilon_{p}^{T}=\frac{2}{\sqrt{3}}\left[2 \cot \left(\frac{\Phi}{2}+\frac{\Psi}{2}\right)+\Psi \operatorname{cosec}\left(\frac{\Phi}{2}+\frac{\Psi}{2}\right)\right]
$$

Figure 2 shows the variation of the total equivalent plastic strain for different combinations of corners angles $\Psi_{1}$ and $\Psi_{2}$ when the channels angles $\Phi_{1}=\Phi_{2}=\Phi=90^{\circ}$. It can be seen that the high value of plastic deformation $\varepsilon_{p}^{T}=2.31$ is obtained when $\Psi_{1}=\Psi_{2}=0^{\circ}$. Then, as the corner angles increase, the plastic deformation decreases until a minimum value of 1.81, which is obtained when $\Psi_{1}=\Psi_{2}=90^{\circ}$. Consequently, to obtain high levels of plastic deformation, it is advised to use corners angles close to $0^{\circ}$.

According to the above equations, the plastic strain is dependent only on the two angular quantities of $\Phi$ and $\Psi$ and does not take into account the length of the second channel. Moreover, these equations basically assume homogeneous deformation over the whole sample, and do not provide an explanation for the non-uniform deformation induced in the extruded sample. Hence, in order to investigate such a nonuniform deformation and optimize the geometrical parameters of the 2-ECAE die, the finite element method (FEM) seems to be the most adequate tool and was adopted in the following sections.

\section{FINITE ELEMENT MODELLING}

The isothermal two-dimensional finite element simulations under plane-strain conditions are considered. The simulations have been carried out using the finite element software MSC.Marc $^{(}$with a mesh of 4400 four-node isoparametric elements for a sample of $\mathrm{w} \times \mathrm{t} \times \mathrm{L}=10 \times 10 \times 110 \mathrm{~mm}^{3}$. In order to obtain a high level of plastic deformation, the elbows angles were taken as $\Phi_{1}=\Phi_{2}=\Phi=90^{\circ}$ and the two outer corners angles have been fixed to $10^{\circ}$. The friction factor between the die and the sample was assumed to be $0^{\circ}$ (i.e. frictionless condition) for the first tests. Then, it was changed to highlight its influence. The die and ram were considered as rigid bodies in the modeling. The displacement of $110 \mathrm{~mm}$ was assigned to the ram in the extrusion direction with a constant speed of $10^{-1}$ $\mathrm{mm} / \mathrm{s}$. A radii $\mathrm{r}=2 \mathrm{~mm}$ has been taken at the inner corners. It should be noted that this value has been selected according to a study on the effect of the inner radius described in [14]. The sample behavior was considered as being elastic perfectly plastic. In order to control the plastic strain distribution, the selected cross-section was taken at $20 \mathrm{~mm}$ below the second inner corner (see Figure 3).

\section{RESUlTS AND DISCUSSION}

\section{A. Equivalent plastic strain distribution}

In ECAE process the homogeneity of the plastic strain distribution in the bulk material during successive passes is very important. The aim of this section is to determine the optimal conditions which allow us to improve the homogeneity of the plastic strain distribution in terms of width and length of the second channel for the two-elbows device.

Figure 4 shows the plastic strain distribution for six different lengths $\mathrm{L}=\{10,15,20,30$ and $50 \mathrm{~mm}\}$ with a section of $\mathrm{w} \times \mathrm{t}=10 \times 10 \mathrm{~mm}^{2}$ and an inner corner radii of $2 \mathrm{~mm}$. It can be observed that the plastic strain is not uniform along the samples width during the first pass. However, in the second pass, the homogeneity of the plastic distribution is relatively improved except the case of $\mathrm{L}=10 \mathrm{~mm}$. This can be attributed to the vacuum created at the outer corner of the second elbow. For more details, we have shown in Figure 5, the distribution of the equivalent plastic strain in terms of the distance from the bottom along the selected cross-section of the sample for each width with different lengths of the second channel. It can be seen that the best homogeneity of the plastic strain distribution was obtained with a length of $30 \mathrm{~mm}$ and a width of $10 \mathrm{~mm}$, which is the same of those of the entrance and the exit channels. Moreover, one can note that the maximum heterogeneous plastic deformation is always obtained with a length of $10 \mathrm{~mm}$ regardless the width of the second channel.

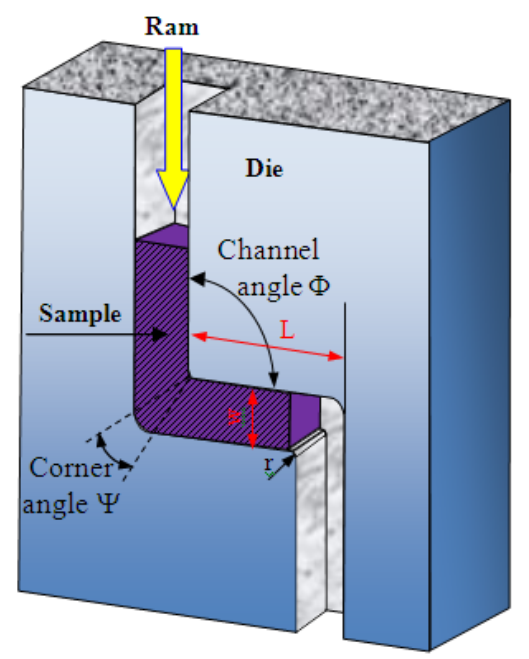

Fig. 1. Schematic illustration of two turn equal channel angular extrusion process. 

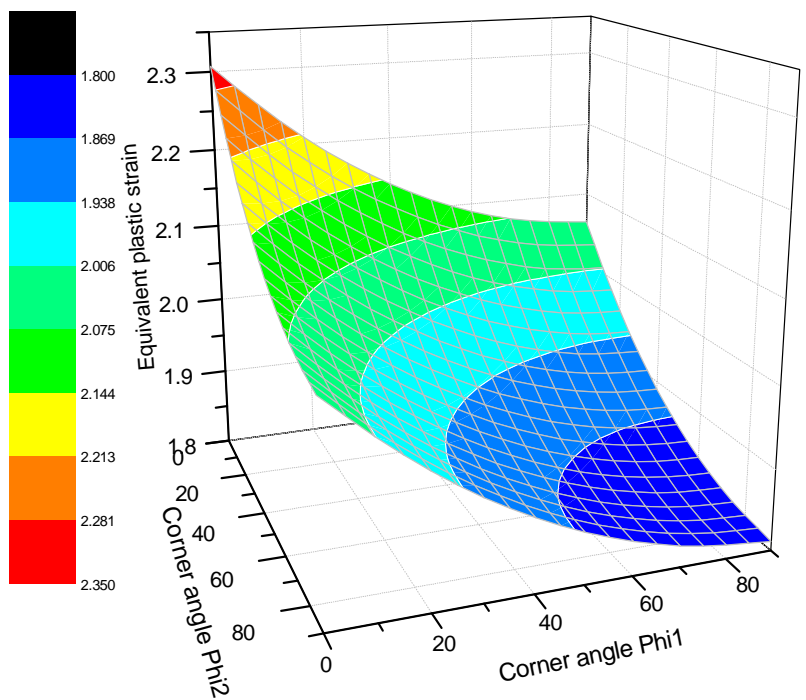

Fig. 2. Variation of the total equivalent plastic strain for different combinations of corners angles when the elbows angles $\Phi 1=\Phi 2=\Phi=90^{\circ}$.

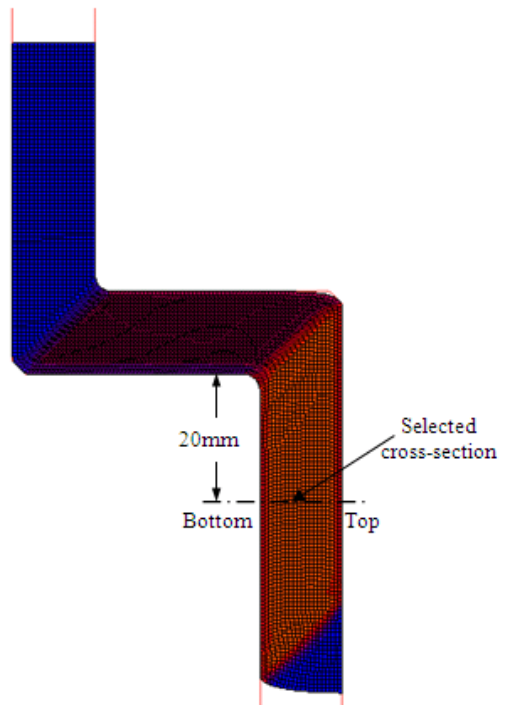

Fig. 3. Illustration of the finite element mesh of the sample and the selected cross-section for the measurement.
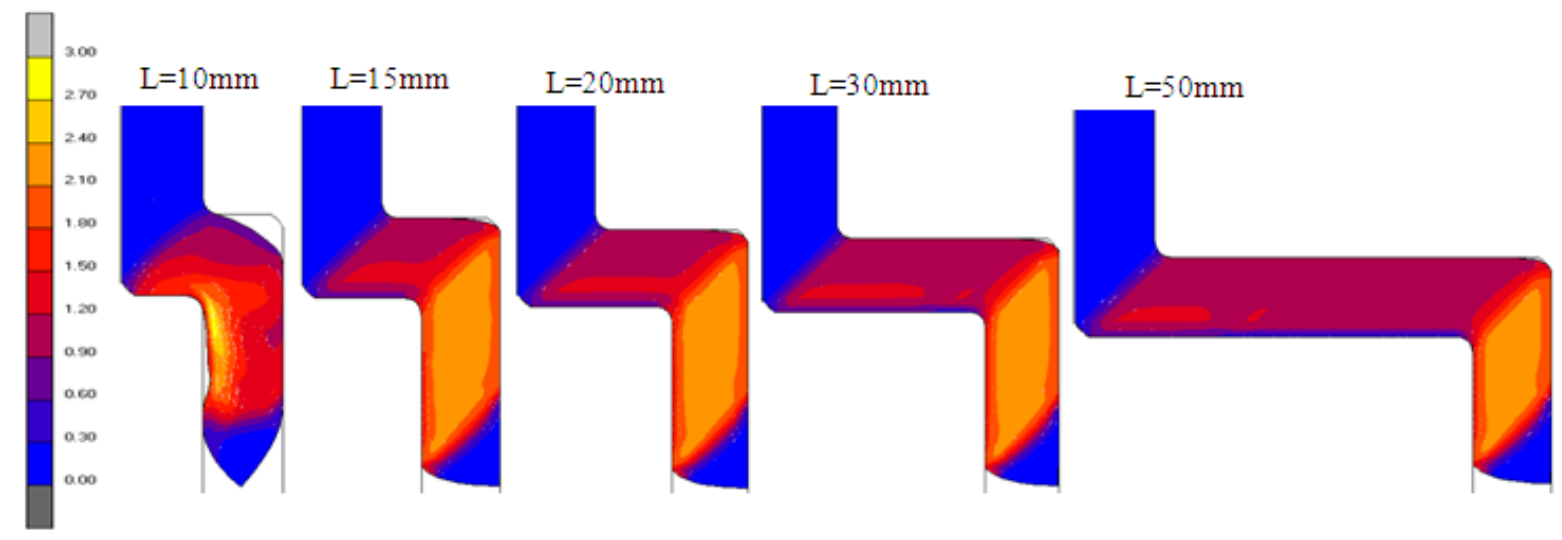

Fig. 4. Equivalent plastic strain contours of the samples for different lengths

\section{B. Evolution of the pressing force}

The magnitude and distribution of plastic strain in the sample can be seen as key parameters for the ECAE process. The magnitude of the pressing force required to extrude the material defines the practical limit of the extrusion tool. The numerical results of the pressing force required for extrusion were calculated from the nodal forces in the top of the sample. This force is depicted versus time in Figure 6 for different widths (w) and lengths (L) of the second channel. In general, at the beginning of the extrusion, the pressing force starts to increase quickly as soon as it contacts the first outer corner of the second channel. At this level, there will be initiation and growth of the shear band until the sample head crosses entirely the first elbow (up to the stability of the material flow). The first plateau of the curve corresponds to the steady state of the plastic flow for the first pass. It should be noted that the length of this plateau increases with the increase of the length of the second channel. The second increase in the pressing force will take place when the sample comes into contact with the second elbow. After it crosses the second plastic deformation zone, a second plateau with a slight undulation is observed. This can be attributed to the interaction between the plastic deformations induced by the both elbows of the tool.

In the case of different widths with a fixed length of $30 \mathrm{~mm}$ (Figure 6a), it can be seen that the pressed force increases rapidly when the width is small and the force required for the second pass is approximately two times the force of the first pass. In general, a slight influence of the width on the maximum required force (which is about $3000 \mathrm{~N}$ ) is noticed. However, in the case of different lengths with a fixed width of $10 \mathrm{~mm}$ (Figure 6b), it can be observed that the extrusion force increases quickly when the length is small and the force required for the second pass is slightly higher than twice the force of the first pass except for that of $\mathrm{L}=10 \mathrm{~mm}$, in which, a value of $2400 \mathrm{~N}$ is recorded. In general, the maximum required force for different lengths does not exceed $3000 \mathrm{~N}$. 


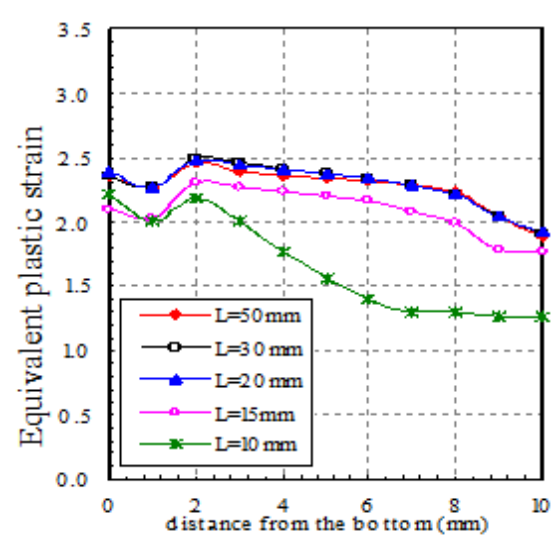

(a) $\mathrm{w}=7 \mathrm{~mm}$

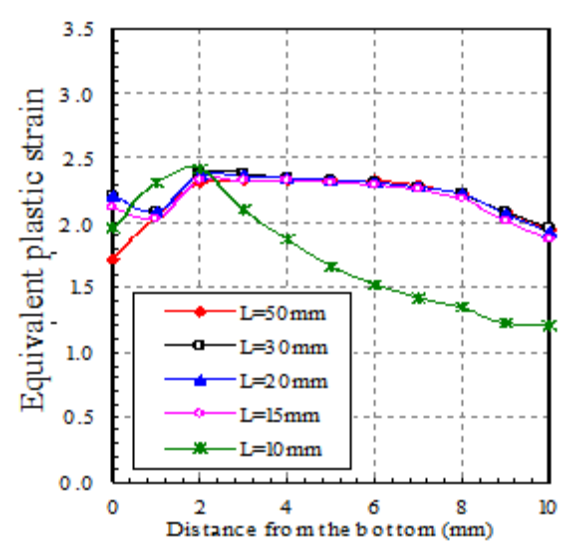

(b) $\mathrm{w}=8 \mathrm{~mm}$

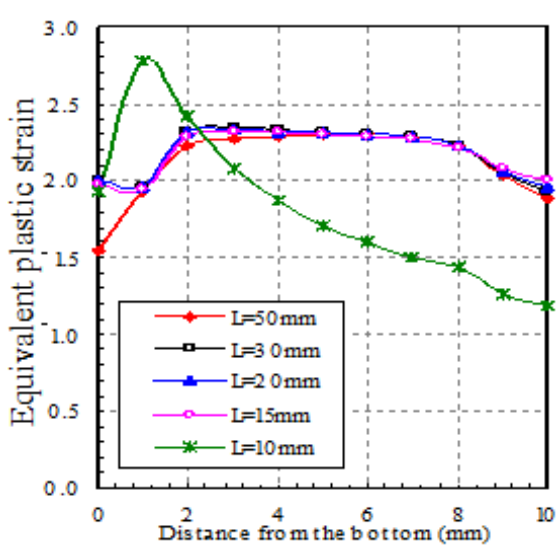

(c) $\mathrm{w}=9 \mathrm{~mm}$

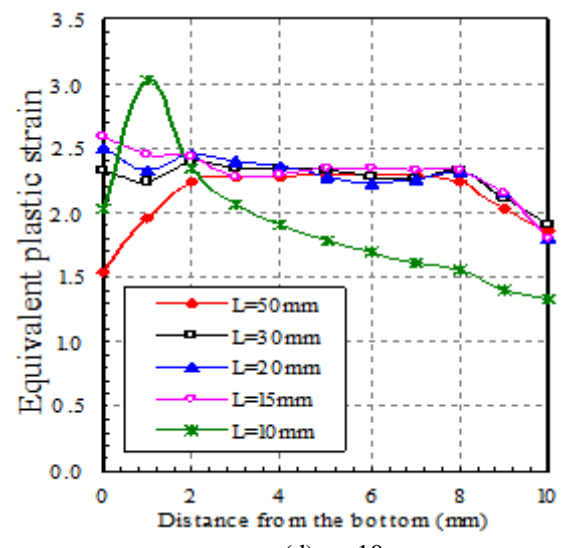

(d) $\mathrm{w}=10 \mathrm{~mm}$

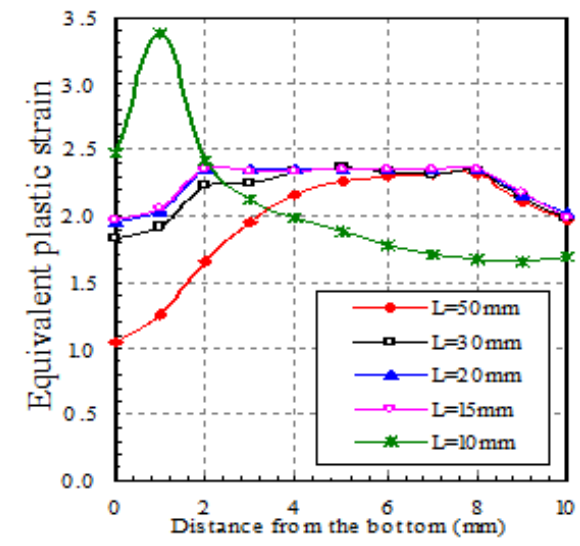

(e) $\mathrm{w}=12 \mathrm{~mm}$

Fig. 5. Influence of the length of the second channel on the distribution of the plastic strain for different values of widths

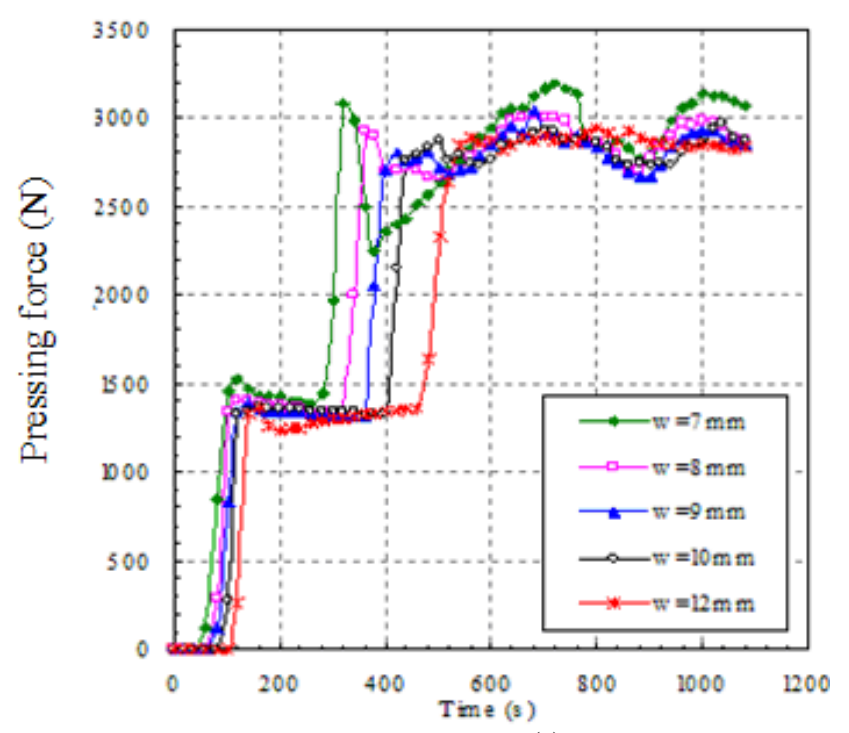

(a)

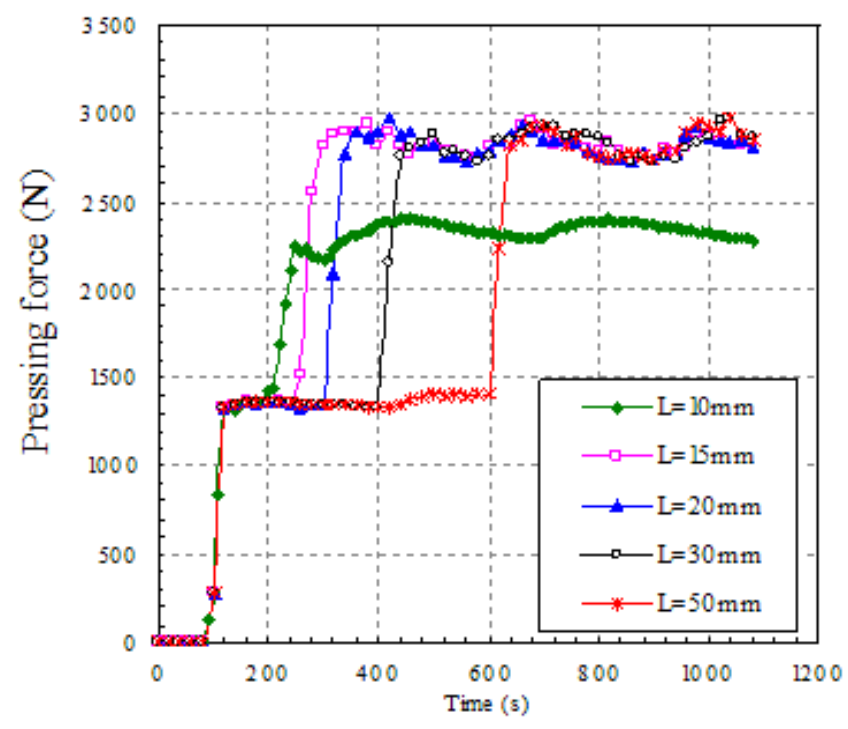

(b)

Fig. 6. Variation of pressing force for different (a) widths with $\mathrm{L}=30 \mathrm{~mm}$ and (b) lengths with $\mathrm{d}=10 \mathrm{~mm}$ 


\section{Variation of equivalent plastic strain rate}

In order to reveal the spatial variation of plastic strain and the trends in the degree of in-homogeneity originated in plastic deformation zone (PDZ) development, the strain rate distribution within the first and the second elbow is considered when $\mathrm{L}=30 \mathrm{~mm}$ for $\mathrm{w}=\{7,10$ and $12 \mathrm{~mm}\}$ (Figure 7). It can be seen that the best results were obtained at the second pass for $\mathrm{w}=10 \mathrm{~mm}$. To confirm this result, we plotted (Figure 8), the maximum difference in equivalent plastic strain rate in the case of the first pass and the second pass. The values are given for top, middle and bottom material points (1,2 and 3) as shown in Figure 7 . It can be seen that the minimum difference in the equivalent plastic strain rate was obtained for a width (of the second channel) equal to $30 \mathrm{~mm}$.

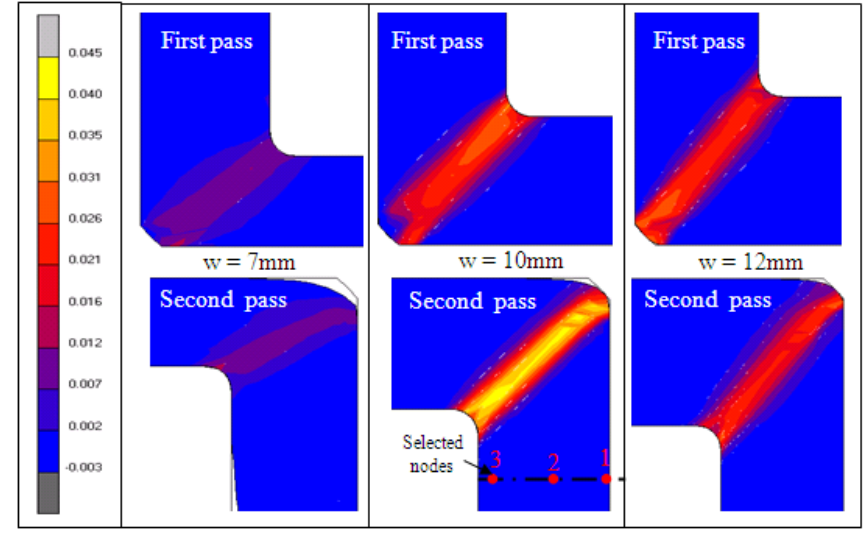

Fig. 7. Variation of equivalent plastic strain rate for $L=30 \mathrm{~mm}$ and $w=\{7$, 10 and $12 \mathrm{~mm}\}$

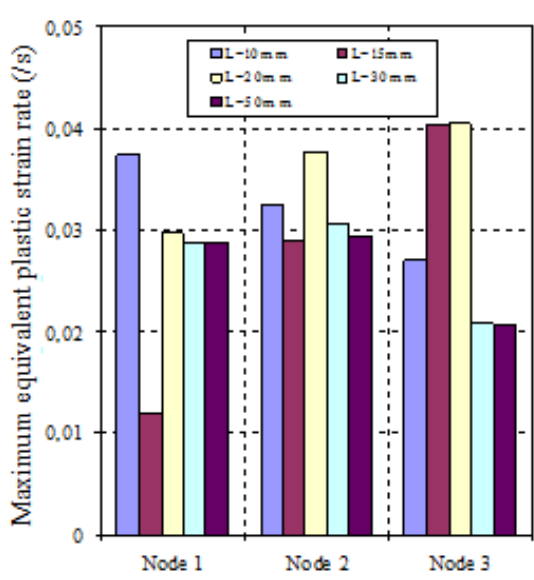

(a) First pass

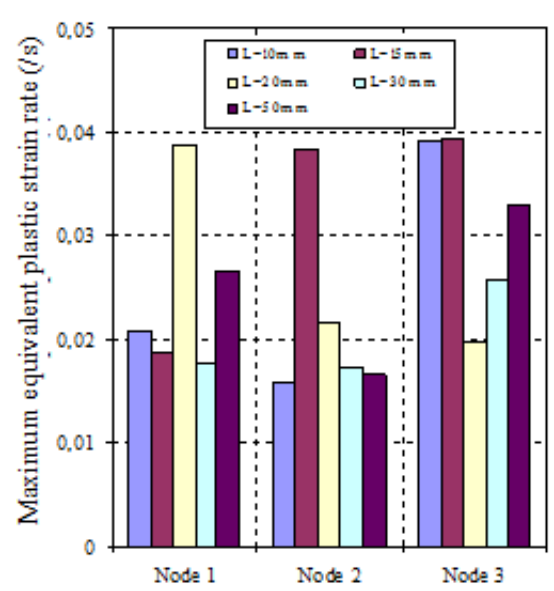

(b) Second pass

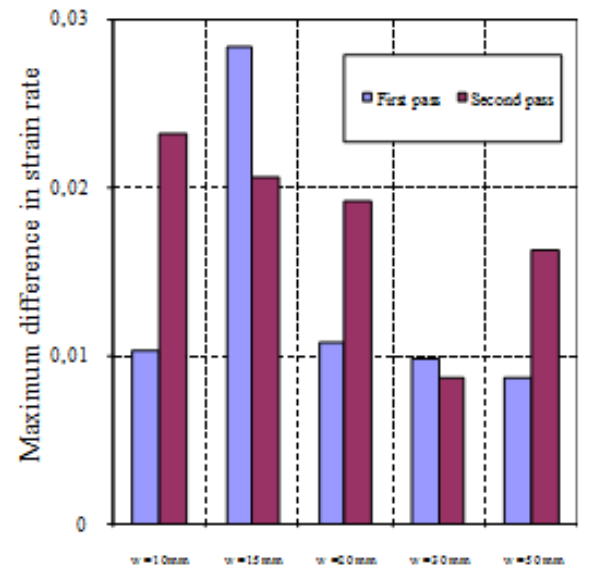

(c) Max. difference in $\dot{\varepsilon}$.

Fig. 8. Variation of equivalent plastic strain rate in the case of (a) first pass, (b) second pass and (c) the maximum difference in equivalent plastic strain rate.

\section{Effect of friction}

In above sections, we have assumed that the friction between the sample and the tool walls is negligible (i.e. frictionless condition). In this section, the friction effects on the equivalent plastic strain distribution and the pressing force are investigated on the optimized geometry of 2-ECAE tool (with $\mathrm{w}=10 \mathrm{~mm}$ and $\mathrm{L}=30 \mathrm{~mm}$ ). The friction between the tool and the sample is modeled using Coulomb friction law. The computations have been performed with three friction coefficients $f=\{0.2,0.3$ and 0.5$\}$. Figure 9a shows the plastic strain distribution across the width of the sample for different friction conditions. It can be seen that the friction coefficients influence slightly the homogeneity and the magnitude of the equivalent plastic strain. This can be attributed to the perfectly plastic behavior of the considered material and to the tool geometry which improves the flow capability of the material and hence, weakens the friction effect.

It should be noted however, that the extrusion force may not be independent of friction, even though the strain clearly is. Figure 9b shows the friction effect on the actual values of the pressing force required for extrusion. It can be noted that the maximum force required at each friction coefficient is approximately $3000 \mathrm{~N}$ (for $\mathrm{f}=0$ ), $3350 \mathrm{~N}$ (for $\mathrm{f}=0.2$ ), $3620 \mathrm{~N}$ (for $\mathrm{f}=0.3$ ) and $4300 \mathrm{~N}$ (for $\mathrm{f}=0.5$ ). One can observe that the friction plays a significant role on the magnitude of the force required for extrusion. Indeed, the difference between the forces required for extrusion with significant $(\mathrm{f}=0.5)$ and neglected frictions can reach about $50 \%$. Therefore, in order to reduce the friction effect and the pressing force required for extrusion, it is better to conduct the 2-ECAE process with an appropriate lubricant.

\section{CONCLUSION}

In this present study, the finite element method was used to provide fruitful information on the plastic strain distribution in the extruded material using a two turn ECAE die. From a broader perspective, it can be understood that the deformation is more complicated with two turn $90^{\circ}$ die compared to conventional ECAE die, and so are the plastic strain behaviors. It was found that the length and the section of the second channel play a significant role on the homogeneity of the plastic strain distribution and the pressing force required for material 
extrusion. We noticed that the minimal force was obtained by the minimum length of the second channel $(\mathrm{L}=10 \mathrm{~mm})$. However, the best homogeneity of plastic deformation was obtained for a die with equal sections and a length of $30 \mathrm{~mm}$ for the second channel. A slight sensitivity of plastic strain distribution to friction conditions between samples and die was indicated. To reduce the friction effect on the magnitude of the pressing force, it is advised to use an appropriate lubricant during the process. Furthermore, it is worth noting that by using

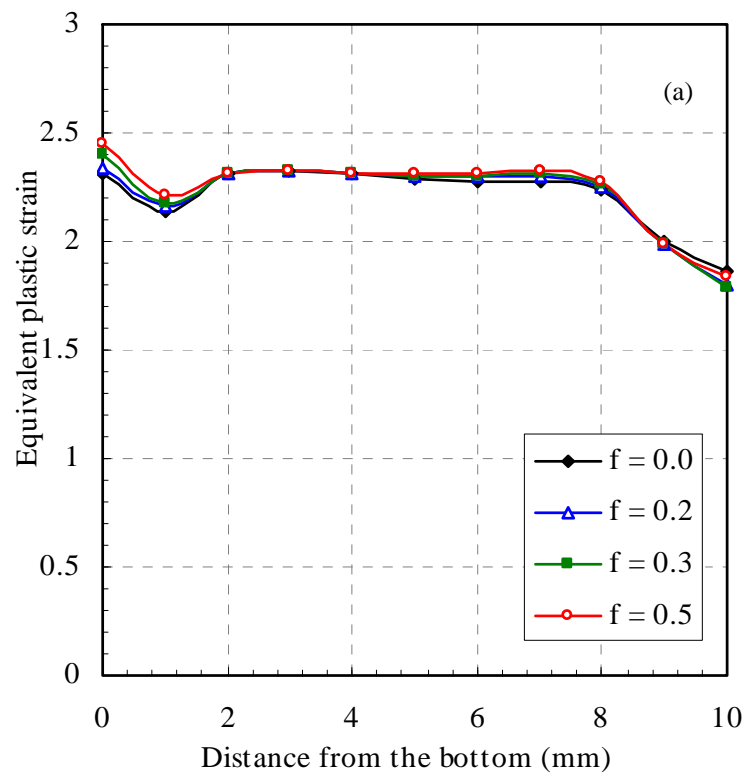

the two-turn channels the plastic strain in one pass becomes double and the productivity of the ECAE process increases enormously. Finally, in order to take advantage of this optimized 2-ECAE process, it is essential to combine the modeling analysis of the deformation behavior of samples with experimental tests. Hence, a new ECAE die with the proposed geometry is to be manufactured in the near future, in order to obtain experimental data on the microstructural and mechanical aspects.

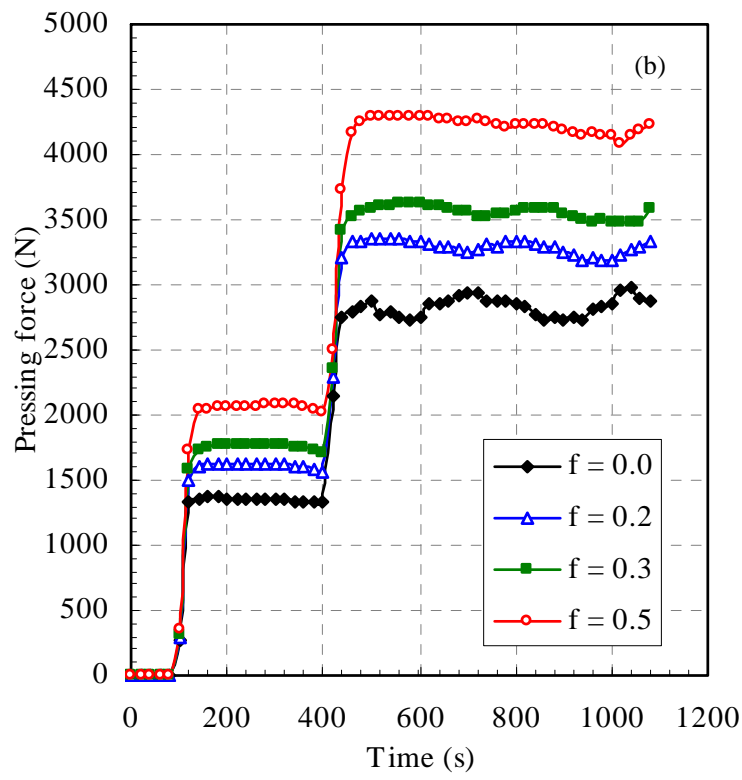

Fig. 9. Effect of the friction sample/die channels on the evolution of (a) the equivalent plastic strain and (b) the pressing force

\section{REFERENCES}

[1] V. M. Segal, "Materials processing by simple shear”, Materials Science and Engineering:A, Vol. 197, No. 2, pp. 157-164, 1995

[2] Y. Iwahashi, J. Wang, Z. Horita, M. Nemoto, T. G. Langdon, "Principle of equal-channel angular pressing for the processing of ultra-fine grained materials ”, Scripta Materialia, Vol. 35, No. 2, pp.143-146, 1996

[3] S. L. Semiatin, D. P. Delo, E. B. Shell, "The effect of material properties and tooling design on deformation and fracture during equal channel angular extrusion”, Acta Materialia, Vol. 48, No. 8, pp. 1841-1851, 2000

[4] P. N. Fagin, J. O. Brown, T. M. Brown, K. V. Jata, S. L. Semiatin, "Failure modes during equal channel angular extrusion of aluminum alloy 2024”, Metallurgical and Materials Transactions A, Vol. 32, No. 7 , pp. 1869-1871, 2001

[5] R. B. Figueiredo, P. R. Cetlin, T. G. Langdon, "The evolution of damage in perfect-plastic and strain hardening materials processed by equalchannel angular pressing”, Materials Science and Engineering: A, Vol. 518, No. 1-2, pp. 124-131, 2009

[6] C. K. Y. Li, Z. Y. Xia, H. J. Sue, "Simple shear plastic deformation behaviour of polycarbonate plate. II: Mechanical property characterization”, Polymer, Vol. 41, No. 16, pp. 6285-6293, 2000

[7] H. J. Sue, H. Dilan, C. K. Y. Li, "Simple shear plastic deformation behavior of polycarbonate plate due to the equal channel angular extrusion process. I: Finite element methods modeling", Polymer Engineering and Science, Vol. 39, No. 2, pp. 2505-2515, 1999

[8] F. Zairi, B. Aour, J. M. Gloaguen, M. Nait-Abdelaziz, J. M. Lefebvre, "Influence of the initial yield strain magnitude on the materials flow in equal-channel angular extrusion process”, Scripta Materialia, Vol. 56, No. 2, pp. $105-108$

[9] B. Aour, F. Zairi, M. Nait-Abdelaziz, J. M. Gloaguen, J. M. Lefebvre, "Analysis of polypropylene deformation in a $135^{\circ}$ ECAE die: experiments and three-dimensional finite element simulations”, Key Engineering Material, Vol. 424, pp. 71-78, 2010

[10] J. Alkorta, J. G. Sevillano, “A comparison of FEM and upper-bound type analysis of equal-channel angular pressing (ECAP)”, Journal of Material Processing and Technology, Vol. 141, No. 3, pp. 313-318, 2003

[11] I. J. Beyerlein, C. N. Tome, "Analytical modelling of material flow in equal channel angular extrusion (ECAE)”, Materials Science and Engineering: A, Vol. 380, No. 1-2, pp. 171-190, 2004

[12] C. J. Luis Perez, R. Luri, "Upper Bound Analysis of the ECAE Process by Considering Circular Cross-Section and Strain Hardening Materials”, Journal of Manufacturing Science and Engineering, Vol. 132, No. 4, Art. No. 041003, 2010

[13] B. Aour, F. Zairi, J. M. Gloaguen, M. Nait-Abdelaziz, J. M. Lefebvre, "Numerical investigation on equal channel angular extrusion process of polymers”, Computational Materials Science, Vol. 37, No. 4, pp. 491506, 2006

[14] B. Aour, F. Zairi, M. Nait-Abdelaziz, J. M. Gloaguen, O. Rahmani, J. M. Lefebvre, "A computational study of die geometry and processing conditions effects on equal channel angular extrusion of a polymer", International Journal of Mechanical Sciences, Vol. 50, No. 3, pp. 589602, 2008

[15] B. Aour, F. Zairi, J. M. Gloaguen, M. Nait-Abdelaziz, J.M. Lefebvre, "Finite element analysis of plastic strain distribution in multi-pass ECAE process of high density polyethylene”, Journal of Manufacturing Science and Engineering,Vol. 131, No. 3, Art. No. 031016, 2009 